\title{
DOOD OP BESTELLING IN HET ZICHT VAN ALZHEIMER
}

\author{
Patrick Delaere
}

De waarheid is, dat een mens wil leven, tot welke prijs dan ook, hij wil leven omdat hij leeft, omdat de hele wereld leeft. Er is niets dan het leven...

Salmen Lewental

Stel u gaat dood. En u komt daarna geplastineerd in een ludieke pose op de tentoonstelling Body Worlds van dr. Gunther von Hagens te staan. Voegt dit iets toe voor $\mathrm{u}$ aan alles wat $\mathrm{u}$ belangrijk of waardevol hebt gevonden tijdens uw leven? Nee, want u bent dood. Stel nu dat u vóór uw dood te kennen hebt gegeven: "Het geeft niet wat er straks met mijn lichaam gebeurt, zolang het maar niet op een van Gunther von Hagens' tentoonstellingen te kijk wordt gezet.” Doet uw aanwezigheid op de reizende tentoonstelling Body Worlds dan iets af aan alles wat u bij leven belangrijk of waardevol hebt gevonden? Misschien zullen uw nabestaanden dat zo ervaren. Maar u ervaart het in ieder geval niet zo, want u bent dan dood. Wanneer mensen iemands 'laatste wens' respecteren is niet meteen duidelijk hoe dat iets toevoegt aan de belangen of waarden van de aflijvige.

Wilsverklaringen in het zicht van Alzheimer zijn een vergelijkbaar geval. Alzheimerpatiënten stellen wilsverklaringen op, waarin ze bijvoorbeeld vragen om, wanneer ze eenmaal in een ernstige staat van dementie zijn beland, niet (verder) behandeld te worden bij medische complicaties. Of om gedood te worden wanneer ze door ernstige dementie hun 'menswaardigheid' verliezen. Daarbij beroepen ze zich op hetgeen ze in een eerdere levensfase belangrijk of waardevol vonden. Sommige van die waarden en belangen, zo redeneren ze, zijn levensomspannend en gelden ook voor het slothoofdstuk van hun leven, waarin ze verward en niet langer bij machte zijn om hun waarden en belangen te bekrachtigen. Ondanks hun initiële aantrekkingskracht zijn dergelijke wilsverklaringen echter zeer problematisch. Onduidelijk is of en hoe die waarden en belangen met een wilsverklaring 'bekrachtigd' kunnen worden. Wanneer mensen geloven met een wilsverklaring zelf nog iets te kunnen toevoegen of afdoen aan hun eerder geaffirmeerde waarden en belangen in hun toestand van ernstige dementie, maken ze zichzelf misschien iets wijs; en overschatten ze zo het gewicht van wilsverklaringen in het zicht van Alzheimer. Dat is althans wat ik hieronder zal beargumenteren. Eerst sta ik stil bij de parallel tussen wilsverklaringen in het zicht van Alzheimer en testamentaire beschikkingen. Daarna wil ik de morele standaardrechtvaardiging voor het gebruik van wilsverklaringen door alzheimerpatiënten bespreken en bestrijden. En ik eindig met het voorstellen van twee alternatieven voor het gebruik van wilsverklaringen in het zicht van Alzheimer. 


\section{Posthume belangen}

Het valt niet te ontkennen dat veel mensen bij leven proberen om hun posthume belangen te behartigen en dat het doorgaans als een teken van gebrek aan respect voor de overledene wordt beschouwd wanneer met diens laatste wensen geen rekening wordt gehouden. Als iemand vraagt om zijn as uit te laten strooien op de plek in het bos waar hij voor het eerst zijn geliefde heeft bemind, dan zullen de nabestaanden naar verwachting Staatsbosbeheer trotseren en proberen uitvoering te geven aan die laatste wens. Er zijn grosso modo drie soorten belangen van levenden die zich voorbij de grenzen van hun bestaan uitstrekken en zelfs zo dat ook de wetgever daar rekening mee houdt: wensen over hetgeen er met hun dode lichaam gebeuren moet, wensen over hoe er na hun dood met hun bezittingen dient omgegaan te worden, en wensen betreffende hun goede naam en reputatie. Toch is hier sprake van een ongerijmdheid. De dood van de persoon is het moment waarop de betreffende ophoudt te bestaan, terwijl na zijn dood wordt gehandeld in de geest van de overledene alsof deze nog bestond. Strict genomen gaat het hierbij om handelingen die de persoon in kwestie niet meer kunnen raken: het begraven van een lichaam, het verdelen van goederen of het in ere houden van een nagedachtenis. Het valt moeilijk in te zien hoe de belangen van een overledene zodoende nog letterlijk kunnen worden geschaad of behartigd. Dat wil zeggen voor iemand die een (mijn) epicurisch wereldbeeld ${ }^{1}$ als vertrekpunt kiest. Volgens Epicurus is de wereld er een van los zand, van bewegende deeltjes. Komt een mens te overlijden dan ontbindt hij onmiddellijk. Hij valt letterlijk uit elkaar. En dit geldt ook onverkort voor de menselijke geest. De dood is "the total emptiness forever, the sure extinction that we travel to and shall be lost in always". Dat veel mensen (maar ook weer niet iedereen) de laatste wens van de overledene en diens reputatie respecteren in de overtuiging dat ze dit voor de overledene doen of dat ze in het belang van de overledene handelen, kan vanuit epicurisch oogpunt niets meer zijn dan een façon de parler. Alleen in overdrachtelijke zin kunnen de belangen van een dode worden behartigd of geschaad. ${ }^{3}$ Los van belangenbehartiging heeft het opstellen en naleven van testamentaire beschikkingen echter nog een andere werking. Het ten uitvoer leggen van een testament door de nabestaanden is een rituele, symbolische en troostvolle manier om enigszins in het reine te komen met het verlies van hun dierbare. Zoals het eerder ook voor de opsteller die zijn laatste wens kenbaar maakte, een rituele, symbolische en troostvolle manier is geweest om zich schrap te zetten tegen het barre gegeven dat zijn dood onvermijdelijk is. Dat de belangen van een dode alleen in overdrachtelijke zin kunnen worden behartigd of geschaad maakt (het respect voor) iemands laatste wens of reputatie dus niet arbitrair en zonder enig moreel belang. Het is moreel problematisch om een gedane belofte te breken of om iemands reputatie door het slijk te halen; we willen liever niet samenleven met mensen voor wie gedane beloften en de waarachtigheid van reputaties er nauwelijks

1. Het gedachtegoed van Epicurus (341-270) geniet momenteel hernieuwde belangstelling. Een van de meest ambitieuze recente pogingen tot herwaardering van deze filosofische subtraditie ondernam Catherine Wilson in haar historische studie Epicureanism at the Origins of Modernity.

2. Uit Philip Larkins gedicht Aubade.

3. Voor een poging om toch nog een subject aan te wijzen, zie D. Sperling (2008) Posthumous Interests. Legal and Ethical Perspectives. 
toe doen. ${ }^{4}$ Maar denken dat door naleving van een testament iets aan de belangen en waarden van de overleden persoon wordt toegevoegd is, voorzichtig uitgedrukt, dubieus.

\section{Post-personen}

Wilsverklaringen in het zicht van Alzheimer zijn vergelijkbaar met testamentaire wilsbeschikkingen. Dat mag misschien verbazen. Want een belangrijke asymmetrie tussen wilsverklaringen van alzheimerpatiënten en testamentaire beschikkingen is natuurlijk dat de alzheimerpatiënt nog in leven is. In de eindfase van Alzheimer hebben we nog te maken met een bewust menselijk wezen. Alleen, we hebben dan, bedroevend genoeg, niet langer te maken met de menselijke persoon, die ooit de wilsverklaring opstelde. ${ }^{5}$ Alzheimer is een dodelijke ziekte die - tot op heden - niet kan worden gestopt of genezen en waarbij sprake is van een lange afdaling in afhankelijkheid door fysieke en geestelijke aftakeling. De symptomen zijn - onder andere - ernstig geheugenverlies, afasie, visueel-ruimtelijke problemen (apraxie) en apathie. In het huis van dokter Aloïs Alzheimer gaan de lichten één voor één uit. De patiënt is aangewezen op een brein dat progressief wordt verwoest door klonten en verstrengelingen van eiwit, en waarvan gedurende het ziekteverloop een derde verloren gaat. De ernstig dementerende weet niet langer wie hij is, waar hij is, en in welke tijd hij leeft. Hij is 78 maar denkt 20 te zijn. Hij herkent het huis niet meer waar hij dertig jaar lang gelukkig getrouwd heeft geleefd en gaat wanhopig op zoek naar het - inmiddels gesloopte - huis waarin hij is opgegroeid. Hij herkent zijn levenspartner niet meer. Zijn emoties zijn grillig. Zijn gedachten onsamenhangend. Hij kan geen plannen maken noch beslissen wat te doen. Een alzheimerpatiënt leeft tussen de brokstukken van het verleden zonder zicht op een toekomst. De lijm die de persoon doorheen de tijd bijeenhield laat los en stukje bij beetje verdwijnt de persoon, verwordt hij tot een residu van wie hij was. In zekere zin sterft de persoon een mort sans corps. En in zoverre gaat de parallel met een overledene wel degelijk op. Er kan bij ernstig dementerenden eigenlijk geen sprake meer zijn van een persoon, ook niet van een 'andere' persoon. ${ }^{6}$ Wat er rest van de voormalige persoon wordt vooral

4. Moreel problematisch aan het handelen van een executeur-testamentair die zich in stilte niet aan een testament houdt - hij strooit de as van de overledene niet uit in het bos, maar spoelt die door de gootsteen - is dat het een vorm van bedrog is. Niet voor niets voltrekt zijn handeling zich 'in stilte'.

5. Persoon-zijn vat ik in lijn met M. Schechtman (1996) en D. DeGrazia (2005) op als narratief zelfverstaan, als het vermogen om vanuit eerstepersoons perspectief een autobiografisch narratief gaande te houden. Zo’n zelf-narratief organiseert en integreert disparate ervaringen en handelingen synchroon en diachroon tot een min of meer coherent verhalend geheel en constitueert zo de persoon.

6. Ik vind het niet verdedigbaar dat er in het eindstadium van Alzheimer sprake zou zijn van een numeriek andere persoon. We handelen daar ook niet naar. We vragen geen nieuw paspoort aan en sluiten geen ziektekostenverzekering af voor de 'nieuwkomer'.

levend gehouden door de sociale omgeving: anderen houden de persoon in kwestie enigszins in vorm. We kunnen daarom in het eindstadium van Alzheimer het beste 
spreken van een post-persoon, een menselijk wezen dat ooit een menselijke persoon is geweest.

\section{Morele rechtvaardigingen}

Terug naar de wilsverklaring. Het gebruik van zo’n verklaring roept de vraag op waaraan de wilsverklaring het morele gezag ontleent om autoriteit uit te oefenen over de ernstig dementerende post-persoon. Daar zijn verschillende oplossingen voor bedacht. Zo stellen A. Buchanan en D. Brock (1990) de volgende juridisch geïnspireerde morele rechtvaardiging voor. Als we ervan uitgaan dat de demente patiënt geen persoon meer is, dan kunnen ook de rechten die we aan personen plegen toe te kennen niet meer worden geschonden. En, zoals Buchanan en Brock het zien, dan heeft de gezonde persoon "something like a property right...to determine what happens to [his] nonperson successor" (Buchanan en Brock 1990: 166). Met andere woorden: wanneer iemand voorziet dat hij zal veranderen in een post-persoon, dan heeft hij het quasi-eigendomsrecht om controle uit te oefenen over die post-persoon, vergelijkbaar met de wijze waarop iemand mag bepalen wat er na zijn verscheiden met zijn dode lichaam gebeurt. De claim dat quasi-eigendomsrechten mogen worden uitgebreid naar rechten om bewuste menselijke wezens instrumenteel te gebruiken (en eventueel te elimineren) is echter uiterst controversieel en vraagt om verdere verdediging. Want een demente patiënt is niet alleen maar een biologische extensie ('stoffelijk overschot') van de persoon die hij ooit was. Een demente patiënt is een bewust menselijk wezen dat waarde hecht aan zijn ervaringen, wanneer ze positief zijn, van eenvoudig geluk en tevredenheid. Voor zover een demente patiënt in staat is om zijn leven te waarderen, verdient hij moreel respect. Het leven van een dementerende heeft morele waarde op zich, los van de waardetoekenningen die de voormalige persoon heeft neergelegd in zijn wilsverklaring. En die morele waarde stelt grenzen aan de autoriteit van de instructies in die wilsverklaring.

Veel gangbaarder is het om wilsverklaringen in het zicht van Alzheimer te rechtvaardigen zoals Ronald Dworkin (1993) heeft voorgesteld: met een beroep op het publieke beginsel 'respect voor autonomie'. Het debat over persoonlijke autonomie is complex en onbeslecht. Er is inmiddels een variëteit aan voorwaarden te geven voor persoonlijke autonomie en aan opvattingen over wat persoonlijke autonomie precies inhoudt en wat van iemand met een autonome status kan worden verwacht. Volgens sommigen - Joel Anderson (2012) is een van hen - is er zelfs sprake van verschillende autonomie-regimes, die samenhangen met uiteenlopende sociale en historische conteksten. Hoe dit verder ook zij, in de huidige praktijk ${ }^{7}$ van de zorg aan dementerenden is voldoende duidelijk hoe het beginsel 'respect voor (precedente) autonomie' wordt ingezet bij het gebruik van wilsverklaringen. En daar wil ik me in mijn bespiegeling toe beperken. Autonoom zijn is handelen binnen een

\footnotetext{
7. Alle staten in de VS hebben wetgeving over negatieve wilsverklaringen, alsook de meeste provincies van Canada, een aantal Australische staten, Nieuw Zeeland, en een aantal Europese landen waaronder Nederland, België, Denemarken, Frankrijk, Spanje, Oostenrijk, Hongarije, Servië, Georgië en recentelijk Duitsland. Alleen Nederland verleent enige wettelijke status aan positieve wilsverklaringen.
} 
raamwerk van regels die je jezelf stelt, en een soort autoriteit hebben over jezelf, alsook in staat zijn om naar dat gezag te handelen (Oshana 2007). Van wie autonoom een wilsverklaring opstelt veronderstellen we dat hij de autoriteit en het vermogen heeft om zijn persoonlijke zaken te regelen binnen een samenstel van regels (of waarden, principes, overtuigingen, pro-attitudes) die hij zelf heeft gekozen. Tegelijk weten we dat van dit vermogen tot zelfbeschikking weinig meer over is wanneer de betreffende in een toestand van ernstige dementie komt te verkeren. Volgens Ronald Dworkin (en de bio-ethische 'orthodoxie') heeft de opsteller van de wilsverklaring moreel gezag over de latere demente, omdat autonomie de kern uitmaakt van persoonzijn. De autonoom gekozen waarden en belangen van de opsteller overklassen volgens deze rechtsfilosoof de niet-autonoom gekozen belangen en waarden van de ernstig dementerende. Laat me dit verder uitleggen.

In een imposant hoofdstuk gewijd aan dementie, dat de morele discussie over het onderwerp al bijna 20 jaar domineert, maakt Dworkin een onderscheid tussen 'ervaringsbelangen' en 'kritische belangen' (Dworkin 1993: 218-41). Mensen doen allerlei dingen omdat ze de ervaring van het doen van die dingen belangrijk vinden: spinning, lekker koken of voor de veertiende keer de Mattheus Passion gaan beluisteren. Het belang van deze activiteiten schuilt in de kwaliteit van de ervaring, van moment tot moment. Kritische belangen daarentegen zijn belangen die gebaseerd zijn op een waardeoordeel over een leven als geheel, bijvoorbeeld het belang dat ouders hechten aan de voorspoed van hun kinderen of het belang dat mensen hebben bij een menswaardig bestaan. ${ }^{8}$ Een wilsverklaring, zegt Dworkin, moet worden beschouwd als een gezaghebbende weergave van iemands kritische belangen. De autonoom gekozen 'kritische belangen' van de opsteller van een wilsverklaring troeven de minder gewichtige ‘ervaringsbelangen' van de dementerende af. Daarom heeft een wilsverklaring moreel gezag. Volgens Dworkin kan een kritisch belang ook zinvol worden behartigd wanneer de bekrachtiging ervan uit een ver verleden stamt. Zelfs nadat de ouders zijn overleden blijft het zinvol om hun kritisch belang te blijven behartigen. Op dezelfde manier heeft het volgens Dworkin zin om het kritisch belang van een voorheen autonoom persoon, zoals diens belang bij het vermijden van de mensonwaardigheid van dementie, te blijven behartigen, ook al is die persoon inmiddels zijn vermogen tot het maken van autonome keuzes kwijtgeraakt en niet meer in staat om dat kritisch belang te begrijpen. ${ }^{9}$ Helaas levert Dworkin geen enkel

8. Je zou deze waarde met Dworkin 'integriteit' kunnen noemen. Of de wens om je leven als een coherent narratief te leiden; D. Brudney spreekt in dit verband van de waarde 'authenticiteit' (Brudney 2009).

9. Er is tegen Dworkins posittie ingebracht dat 'marginale actoren', zoals alzheimerpatiënten, behandeld dienen te worden als rudimentair competente en autonome personen. Het idee van de tegenstanders is dat zolang er basisvermogens aanwezig zijn als het vermogen om te waarderen (Jaworska 1999), of een basaal emotioneeel vermogen om ergens om te geven (Jaworska 2007 en 2009), of een basaal vermogen om controle uit te oefenen over de eigen ervaringen (S.V. Shriffin in Burley 2004: 195-217), demente patiënten dienen te worden behandeld met 'volledig moreel respect'. Zo’n minimale conceptie van autonomie maakt wilsverklaringen uiteindelijk overbodig. Er kan voor gekozen worden om de actuele belangen en waarden van de ernstig demente bepalend te laten zijn voor diens levensvoering, ook al zijn dat heel andere belangen en waarden dan die voorafgaand aan de periode van 'ontgeesting'. 
argument voor zijn claim dat kritische belangen de belanghebbende overleven, terwijl zijn gedachtengang nogal bevreemdt. Want hoe kan een gebeurtenis op tijdstip-t in iemands belang zijn, wanneer de betrokkene op t niet meer bestaat? Om dit aannemelijk te maken moet het bestaan van zoiets ongewoons als 'terugwerkende causaliteit' voor lief worden genomen.

Verdedigers van een Dworkiniaanse benadering zullen tegenwerpen dat het retrograde effect niet een effect is van het type oorzaak-gevolg maar van waardebepaling. En voor zo'n waardebepaling zou het feit of iemand al of niet overleden is of diep dement, irrelevant zijn. Den Hartogh (2012) bijvoorbeeld stelt dat de waarden die de demente eerder heeft neergelegd in zijn wilsverklaring nooit zijn herroepen, maar alleen "achter de horizon verdwenen”. Daarom tellen ze nog mee bij de evaluatie van wat zijn leven voor hem betekent, ook al kan hij die evaluatie niet langer zelf voltrekken. Het gaat om zijn categorische, kritische belangen, zo vervolgt Den Hartogh, die onverminderd van kracht blijven in de laatste fase van dementie, niet anders dan ze voorheen al deden. Ik ben daar echter niet zo zeker van.

Om te beginnnen zijn menselijke waarden en belangen meestal waarden en belangen 'voor zolang het duurt'. Ook wanneer ze een heel leven viseren. Waarden en belangen zijn minder stabiele grootheden dan Dworkin suggereert; gedurende een mensenleven worden ze geregeld herzien. Ook van mensen met een wilsverklaring op zak, die niet in ontluistering willen eindigen, is bekend dat ze het stadium waarin ze geholpen willen worden soms laten voorbijgaan. Ze willen resoluut doorgaan met leven, en geven geen krimp zelfs wanneer ze - mentaal helder - zichtbaar lijden en in de ogen van hun omgeving niets meer hebben om voor te leven. Niet zelden blijken mensen slechte voorspellers van hun toekomstig welzijn. ${ }^{10}$

Maar los van de beperkte menselijke trouw aan eerder gekozen waarden en belangen: waarom zouden autonoom gekozen kritische belangen van kracht blijven wanneer de betrokkene is overleden of in diepe dementie gedompeld? Voor die aanname vind ik in Dworkins visie geen dwingende redenen. Je zou de aanname in twee deelvragen uiteen kunnen leggen: Wat is precies de ontologische status van kritische belangen? En hoe lang zijn de belangen en waarden die mensen autonoom kiezen eigenlijk van kracht? De eerste deelvraag voert naar een actueel, nog onbeslecht debat over het realiteitsgehalte van waarden. De inzet van dit waardenrealisme-debat kan worden samengevat in termen van het Euthyphrodilemma: Is iets waardevol omdat mensen er waarde aan toekennen? Of waarderen mensen iets omdat het waardevol is? Voor beide hoorns van het dilemma - resp. een subjectivistische en een objectivistische benadering - valt het nodige te zeggen. ${ }^{11}$

10. Alzheimerpatiënten weten niet uit eigen ervaring hoe het is om in een toestand van diepe dementie te verkeren. Natuurlijk, de weg die naar dit late stadium leidt is leedvol zowel voor de patiënt als voor zijn dierbaren, maar voor de patiënt zelf is ernstige dementie - aldus de neuroloog Antonio Damasio "waarschijnlijk een verhulde zegen. In dit late stadium, waarin het bewustzijn zo zwaar beschadigd is, kunnen patiënten onmogelijk weet hebben van de verwoestingen die de ziekte heeft aangericht. Ze zijn schimmen geworden van de mensen die ze ooit waren en verdienen onze liefde en zorg tot het bittere einde, maar ze zijn gelukkig in zekere mate bevrijd van de wetten van pijn en lijden die nog wel gelden voor degenen die hen gadeslaan.” (Damasio 2010: 268) 
Duidelijk is dat wat belangrijk of waardevol wordt gevonden, hoe categorisch ook, het beste kan worden begrepen als belangrijk-voor of waardevol-voor een betrokkene. $^{12}$ En in een wilsverklaring zijn ook nadrukkelijk kritische belangen neergelegd die er voor de betrokkene toe doen en die niet primair om hun algemene of objectieve karakter worden gekozen. Bovendien - en dat brengt mij bij mijn tweede deelvraag - zijn het belangen waarvoor de betrokkene in het verleden autonoom heeft gekozen. Ervan uitgaand dat autonomie best wordt opgevat als soevereiniteit, letterlijk ‘jezelf de wet stellen', hoe lang behouden autonoom bekrachtigde waarden en belangen dan hun geldigheid voor de betrokkene? Mijns inziens valt moeilijk staande te houden dat, zoals bijvoorbeeld L. Ferrero (2002) heeft verdedigd, een autonome keuze alleen maar van kracht is op het moment dat ze wordt gemaakt in een soort van existentialistische uitval. Een autonome keuze kan immers best enige tijd naar de achtergrond ('achter de horizon') verdwijnen zonder dat de kiezer daarmee zijn autonomie verliest. Maar laten gelden, zoals Dworkin lijkt te willen, dat een autonome keuze die mensen op basis van hun waarden en belangen maken bestendig van kracht blijft acht ik evenzeer problematisch. Zolang de betrokkene de mogelijkheid heeft tot latere re-evaluatie is er geen probleem. Maar zonder die mogelijkheid tot herijking staat de betrokkene niet langer aan het roer van zijn eigen leven, maar koerst hij op de automatische piloot, wat er verder ook gebeurt. Zo'n vorm van 'autonomie' heeft trekken van vrijwillige slavernij. Beide extremen geldigheid alleen op het moment van keuze en geldigheid zonder de mogelijkheid van ratificatie - overdrijven volgens mij de reikwijdte van autonomie. Het Sartriaanse voorstel omdat het de houdbaarheid van autonome keuzes te beperkt opvat en Dworkins voorstel omdat het de werking van autonome keuzes te ruim opvat. Een middenkoers lijkt hier de best verdedigbare optie: een noodzakelijke voorwaarde om te kunnen spreken van de belangen en waarden van een autonoom persoon is dat ze worden bekrachtigd door deze persoon. En persoonlijke belangen en waarden blijven van kracht zolang de persoon in kwestie in staat is of op enig moment in de toekomst in staat zal zijn om ze autonoom te beamen of herzien. Zo dient bijvoorbeeld de precedente zelfbeschikking (vastgelegd in een zogeheten zelfbindingsverklaring) van een psychiatrische patiënt die cyclisch ontregelt te worden gerespecteerd, omdat de patiënt na een psychotisch intermezzo weer geheel symptoomvrij kan terugblikken op hetgeen hij heeft beschikt. En zo dient de precedente zelfbeschikking van iemand die in coma geraakt te worden gerespecteerd zolang de kans bestaat dat de betreffende weer uit zijn coma ontwaakt. Komt een persoon echter te overlijden, belandt hij in een irreversibel coma of in een onomkeerbare toestand van ernstige dementie, dan is het in mijn optiek niet langer moreel vereist om in het precedente belang van de

11. Voor mijn argument is het niet nodig om het waardenrealisme-debat hier te beslechten. Zelf denk ik dat waarden verschijnen alsof ze reële kenmerken zijn van de wereld maar dat waarderingen projecties zijn van emotionele attitudes op de ervaring van de wereld.

12. Daarmee is natuurlijk nog niet gezegd dat waarden alleen maar als waarden voor die betrokkene kunnen bestaan en oplossen zodra de betrokkene komt te overlijden. Doorgaans is waardering geen puur individuele aangelegenheid, maar worden waarden door grote groepen mensen gedeeld en overleven zo het wegvallen van een enkele betrokkene. 
betreffende te handelen, omdat er geen belanghebbende persoon meer is en de bindende kracht van de voorliggende wilsverklaring dus is uitgewerkt. ${ }^{13}$ En dan is er nóg een probleem met de courante Dworkiniaanse morele rechtvaardiging van wilsverklaringen in het zicht van Alzheimer. Een probleem van een heel andere aard.

In het morele debat over wilsverklaringen in het zicht van Alzheimer wordt heel vaak de individuele patiënt centraal gesteld. DeGrazia (2005: 159-202) is een voorbeeld. En dat is een onderbeschrijving van hetgeen er moreel op het spel staat. Immers, anderen moeten de wilsverklaring uitvoeren door af te zien van behandeling en de patiënt te laten sterven. ${ }^{14}$ Of door de patiënt euthanatica toe te dienen. Zich beroepend op zijn precedente autonomie vraagt de patiënt potentiële achterblijvers om zijn leven te beëindigen. Maar mag hij anderen ter wille van een voor hem ondraaglijk perspectief opzadelen met de vraag om hem voorgoed uit het leven te verwijderen op een moment dat hij niet lijdt, ook al verklaren die anderen zich daartoe bereid? En wanneer precies moeten ze hem dan verwijderen? Dementie is een zeer heterogeen, complex, ondoorgrondelijk, grillig proces met ups en downs, en veelal - zo beweren experts - zonder ondraaglijk lijden in de eindfase (De Boer e.a. 2007). ${ }^{15}$ Hoe moet het 'omgekeerde verlanglijstje' van de patiënt dan worden geïnterpreteerd? Wanneer de patiënt bijvoorbeeld zijn dierbaren niet meer herkent? Definitief niet meer herkent? Ook wanneer hij nog blij is, lacht, wandelt, drinkt, neuriet, bereikbaar is voor geborgenheid? En wie neemt de uiteindelijke beslissing? De morele kosten voor het doden van een medemens die zich redelijk behaaglijk voelt, niet lijdt en makkelijk kan worden gered, zijn hoog. En voor velen zullen ze opwegen tegen de morele kosten van het verlies van persoonlijke autonomie.

Ik denk dat dit probleem het doel dat met de wilsverklaring wordt beoogd nog verder buiten bereik plaatst. Eerder heb ik al betoogd dat het van weinig realiteitszin getuigt om middels een wilsverklaring en met een beroep op precedente autonomie te pogen om je belangen te behartigen over de periode van je leven waarin je door Alzheimer als autonoom persoon definitief bent uitgewist. Zodra de fase van ernstige dementie inzet beslissen anderen, al of niet in de geest van de wilsverklaring. Daar komt nu bij dat voor deze anderen het verzoek om je uit het leven te verwijderen zeer (te) belastend is. Want, zoals Burms en De Dijn schrijven: "Het blijft 'ons moeder', het blijft de vroeger zo flinke buurvrouw, de patiënte die men persoonlijk kent. Het gaat om mensen met een naam, met een ziel, met een geschiedenis die vervlochten

13. In hoeverre behandelaars zich gebonden voelen door de wilsverklaring is een open vraag. Een wilsverklaring is geen behandelovereenkomst.

14. Hier moet een onderscheid worden gemaakt tussen negatieve en positieve wilsverklaringen. Negatieve wilsverklaringen (afzien van behandeling) worden in verpleeghuizen dikwijls gerespecteerd. Aan positieve wilsverklaringen (doodmaken) wordt doorgaans geen gevolg gegeven.

15. Zie noot 10 .

zijn met dit lichaam en die dat lichaam tot iets anders maken dan een louter toonbeeld van aftakeling” (Burms en De Dijn 2011: 83). ${ }^{16}$ 
Ik kom tot de slotsom dat wie de diagnose Alzheimer krijgt meegedeeld zijn toekomstige bejegening en dood beter niet kan organiseren met behulp van een wilsverklaring. Voor dergelijke wilsverklaringen kan hooguit een bescheiden ondersteunende rol zijn weggelegd.

\section{Twee alternatieven}

Gelukkig zijn er andere opties. Voor personen met de diagnose Alzheimer, die zich geconfronteerd zien met een catalogus aan verschrikkingen (de vrees voor ondraaglijk lijden, tekort aan levenskwaliteit, therapeutische hardnekkigheid, om de familie tot last te zijn, om door de familie gemanipuleerd te worden, voor oneer, decorumverlies zonder dat men dit zelfs maar beseft, het verlies van waardigheid...), staan twee strategieën open als alternatieven voor een wilsverklaring. Eén mogelijkheid is dat wie niet in dementie ten onder wil gaan kan vasthouden aan zijn autonomie door zich tijdig $^{17}$ van het leven te beroven nadat de diagnose Alzheimer is gesteld. Daarmee is niet gezegd dat het beter is om dood te zijn dan dement. Maar voor sommige mensen is autonomie, meester zijn over het eigen leven inclusief toekomstige verzorging, een gekoesterde waarde die onopgeefbaar is en waardevoller dan het leven zelf. Zij willen kost wat kost controle houden over hun leven en voorkomen dat ze terechtkomen in wat ze beschouwen als een verward en verloren bestaan. ${ }^{18}$ Voor deze patiënten is Romana mors, sterven in eigen beheer in het zicht van Alzheimer, een moreel te rechtvaardigen daad van autonomie, een ultieme poging om het leven in eigen hand te houden door het te verliezen. In Chabot en Braam (2012) worden drie methoden voor menswaardige zelfdoding ('zelf-euthanasie') besproken. Men kan ervoor kiezen om bewust te versterven, d.i. stoppen met eten en drinken bij voorkeur onder begeleiding van een arts. De tweede methode is het verzamelen van de juiste hoeveelheid van een dodelijk middel. En als derde mogelijkheid wordt de heliummethode beschreven.

16. Hoewel strict genomen (zie noot 5) persoon-zijn niet meer aan de orde kan zijn, blijft de patiënt verweven met de zelf-narratieven van anderen. Daarnaast is het in de praktijk lastig om aan te geven wanneer een persoon ophoudt een persoon te zijn, i.e. om een scherpe lijn te trekken tussen personen en post-personen. Net als bij de overgang van mens-zijn naar persoon-zijn dient hier enige ontologische vaagheid voor lief genomen te worden.

17. Het precieze tijdstip vaststellen waarop men uit het leven stapt is een praktisch probleem dat herinnert aan de moeilijkheden bij het vaststellen van het tijdstip waarop een wilsverklaring uitgevoerd dient te worden. Een relevant verschil is dat het bij zelfdoding om het bepalen van het eigen levenseinde gaat en bij de uitvoering van een wilsverklaring om het timen van het levenseinde van anderen.

18. Vaak wil men ook verschoond blijven van de narigheid die aan de fase van ernstige dementie voorafgaat.

Door de hand aan zichzelf te slaan blijft men aan het roer van het eigen leven, belast men anderen niet met de uitvoering van euthanasie ${ }^{19}$, en betaalt men daarvoor ook een 
prijs: er moet tijd van leven worden ingeleverd. Men sluit zijn leven af op een moment dat men nog in staat is te beschikken. Dat is een tragische en pijnlijke keuze.

Er is nog een tweede alternatief voor de wilsverklaring in het zicht van Alzheimer. Personen kunnen ook accepteren dat autonomie niet langer een issue zal zijn in hun toekomstige incompetente toestand van ernstige dementie en dat ze afhankelijk zullen zijn van de hulp van anderen om beschermd te worden tegen letsel en krenking. Natuurlijk kunnen personen ook dan nog vooraf een wilsverklaring opstellen. Misschien brengt een wilsverklaring troost en rust voor de betreffende in het zicht van Alzheimer, evenals voor de betrokken 'nabestaanden' die in de geest van de wilsverklaring kunnen handelen. Maar men hoeft die rust en troost niet per se te laten afhangen van een wilsverklaring. Iemand kan ook volledig vertrouwen op zijn dierbaren en hen vrijelijk laten beslissen over zijn toekomstige, onbekende lot. ${ }^{20}$ Legt deze tweede optie een te zware morele last op de schouders van vrienden en familie? Ik vind van niet. Iemand die lijdt aan ernstige dementie mag dan uitgeboekt zijn als persoon, hij is nog steeds mens. 'Een van ons', iemand die zijn mens-zijn gemeenschappelijk heeft met ons, graag wil leven ${ }^{21}$ en moet kunnen rekenen op ons respect voor zijn specifieke, kwetsbare en onvervangbare mens-zijn.

\section{Concluderend}

Ik heb betoogd dat het morele gewicht van wilsverklaringen in het zicht van Alzheimer wordt overschat. Wanneer een patiënt zijn persoonlijke levensverhaal en het 'kritische' waardenpatroon dat zijn leven heeft bepaald definitief kwijt is, doet hetgeen hij ooit als persoon autonoom heeft bepaald er voor die patiënt niet meer toe. De patiënt is het perspectief op zijn leven en zijn kritische belangen verloren. En de bindende kracht van hetgeen hij in betere tijden heeft beschikt en in een wilsverklaring heeft neergelegd is uitgewerkt, omdat hij niet langer in staat is, noch

19. Misschien impliceert de aanspraak op een moreel recht om zelf je dood te bewerken ook wel een morele plicht om het zelf te doen: "Met welk moreel recht (...) kan de ene mens de andere mens vragen hem/haar vóór het intreden van bepaalde omstandigheden te doden, èn kan die andere mens dan op dat verzoek ingaan, terwijl het voor die ene mens mogelijk is zélf op een zorgvuldige wijze het leven te beëindigen om daarmee het intreden van de bewuste omstandigheden (i.c. geestelijke verduistering door dementie) te voorkomen? Bij wie ligt hier de verantwoordelijkheid?” (Vink 2012: 34-5)

20. Men kan desgevallend een familielid of dierbare machtigen om beslissingen te nemen, eventueel ook te beslissen over al of niet (verder) behandelen bij medische complicaties.

21. Mensen met een ernstige ziekte schatten hun kwaliteit van leven veelal hoger in dan de omgeving. Het is een vorm van adaptatie die zich bij kwaliteit-van-levenmeting uit als zgn. 'response shift': het veranderen van de eigen waardering van de kwaliteit van leven door herijking en wijziging van prioriteiten en concepten. Over wat kwaliteit van leven precies is bestaat overigens geen overeenstemming.

op enig moment in de toekomst in staat zal zijn, om het te ontkennen of te beamen. Een ernstig demente patiënt die aan het leven hangt uit dat leven verwijderen alleen 
op grond van wat hij in zijn wilsverklaring heeft bepaald, is moreel niet te rechtvaardigen. Richtinggevend voor de bejegening van de patiënt dienen eerst en vooral diens actuele 'ervarings'-belangen en waarden te zijn. Er zijn andere en moreel beter verdedigbare manieren om te anticiperen op de komst van Alzheimer. Voor wie aan het roer wil blijven van zijn eigen leven en de déconfiture van de ziekte van Alzheimer wil vermijden staat de mogelijkheid open om op zorgvuldige wijze de hand aan zichzelf te slaan. Zo'n wilsdood verdient respect en maakt wilsverklaringen overbodig. Een tweede mogelijke strategie is dat men vertrouwt op zijn medemensen en die laat beslissen over zijn lot, vanuit het besef dat controle en diepgekoesterde kritische belangen misplaatst zijn in de onberekenbare jungle die dementie heet. Ook deze tweede strategie maakt wilsverklaringen welbeschouwd overbodig.

Met dank aan Govert den Hartogh en een anonieme reviewer voor hun bereidheid om mijn ideeën in een eerder stadium van streng commentaar te voorzien.

\section{Literatuur}


- Anderson, J. (2012) How autonomous should we expect each other to be? (manuscript)

- Boer, de M. E., C. M. P. M. Hertogh, R. M. Droës, et al (2007) Suffering from dementia the patient's perspective: a review of the literature, International Psychogeriatrics 19, pp. 1021-39

- Brudney, D. (2009) Choosing for another. Beyond autonomy and best interests, Hastings Center Report 39 (2), pp. 31-37

- Buchanan, A. E., en D. W. Brock (1990) Deciding for Others: The Ethics of Surrogate Decision Making. Cambridge: Cambridge University Press

- Burley, J. (red.) (2004) Dworkin and his critics: with replies by Dworkin. Oxford: Blackwell Publishing

- Burms, A., en H. De Dijn (2011) De sacraliteit van leven en dood. Voor een brede bioethiek. Kalmthout: Uitgeverij Pelckmans

- Chabot, B., en S. Braam (2012, vijfde gewijzigde druk) Uitweg. Een waardig levenseinde in eigen hand. Amsterdam: Nijgh \& Van Ditmar

- Damasio, A. (2010) Het zelf wordt zich bewust. Amsterdam: Wereldbibliotheek

- DeGrazia, D. (2005) Human Identity and Bioethics. Cambridge: Cambridge University Press

- Dworkin, R. (1993) Life's Dominion: An Argument About Abortion, Euthanasia and Individual Freedom. London: HarperCollinsPublishers

- Ferrero, L. (2002) Making Up One’s Self. Ph. D. Dissertation, Harvard University

- Hartogh, G. den (2012) The authority of advance directives (manuscript)

- Jaworska, A. (1999) Respecting the margins of agency: Alzheimer's patients and the capacity to value, Philosophy and Public Affairs 28, pp. 105-38

- Jaworska, A. (2007) Caring and full moral standing, Ethics 117, pp. 460-97

- Jaworska, A. (2009) Caring, minimal autonomy, and the limits of liberalism, in: H.

Lindemann, M. Verkerk, en M. Urban Walker (red.) Naturalized Bioethics. Cambridge:

Cambridge University Press, pp. 80-105

- Oshana, M. (2007) Autonomy and the question of authenticity, Social Theory and Practice 33 (3), pp. 411-29

- Sperling, D. (2008) Posthumous Interests. Legal and Ethical Perspectives. Cambridge: Cambridge University Press

- Vink, T. (2012) Dementie en (zelf)euthanasie, lessen uit de praktijk, Tijdschrift voor Gezondheidszorg en Ethiek 22 (2), pp. 34-39

- Wilson, C. (2008) Epicureanism at the Origins of Modernity. Oxford: Oxford University Press 
